\title{
Does continuous renal replacement therapy favourably influence the outcome of the patients?
}

\author{
S. M. Jakob, F. J. Frey and D. E. Uehlinger \\ Division of Nephrology, Department of Medicine, University of Berne, Inselspital, CH-3010 Berne, Switzerland
}

\begin{abstract}
Continuous haemodialysis and continuous haemofiltration are efficient and safe techniques for the treatment of acute renal failure. Theoretical advantages are improved haemodynamic stability and easier fluid removal. All 15 available studies comparing intermittent (522 patients) with continuous (651 patients) renal replacement therapy have been reviewed. From these studies it cannot be established, whether the use of a continuous instead of an intermittent treatment modality improves the outcome in patients with acute renal failure. Reviewing all 67 published studies dealing with continuous renal replacement therapy revealed a trend to a decreasing mortality rate $(P<0.08)$ over the last 11 years, whereas the mean age and the severity of illness of the patients, measured by the APACHE II score, did not change. In order to establish whether the quality of treatment has improved as a function of time, two quality factors $(\mathrm{QF})$ were created, i.e. $\mathrm{QF}$ for age (mean age/mean mortality rate of the patients treated) and QF for severity of diseases (mean APACHE II/mean mortality rate). Both QF improved from 1984 until 1994, when analyzed for continuous $(P<0.001)$ or intermittent $(P<0.001)$ treatment modality. Thus the quality of treatment of patients with acute renal failure improved during the last decade. However, there is no evidence with respect to survival rate that a continuous renal replacement therapy is superior to an intermittent one.
\end{abstract}

Key words: acute renal failure; continuous haemodialysis; continuous haemofiltration; mortality

\section{Introduction}

Since the introduction of continuous haemofiltration [1] and continuous haemodialysis [2], these techniques with several modifications have turned out to be efficient and save [3-5]. Despite the theoretical advantages of continuous forms of renal replacement therapy

Correspondence and offprint requests to: Dominik E. Uehlinger, Division of Nephrology, Department of Medicine, Inselspital, CH-3010 Berne, Switzerland.
(RRT), such as improved haemodynamics [6], easier fluid removal $[6,7]$ and greater flexibility with parenteral nutrition [7], continuous therapies might have some drawbacks: if the coagulation parameters in the patient are normal and a reasonable life-span of the filter has to be obtained, anticoagulation is compulsory. Possibly, there is an increased frequency of access related complications [3]. Furthermore, once very simple and possibly the cheapest form of RRT, todays continuous methods include highly sophisticated treatment devices to guarantee treatment safety and are thought to be some 2.5 times more expensive than conventional intermittent dialysis and/or haemofiltration $[8,9]$. This difference might even be more pronounced if one considers the additional manpower required. Thus, in order to be cost effective morbidity and mortality of patients with acute renal failure (ARF) should be better when a continuous instead of an intermittent RRT is applied.

Although there is some evidence that slow continuous techniques in comparison with conventional (intermittent) RRT might improve morbidity and mortality of patients with ARF [10-12], prospective controlled trials comparing the different forms of RRT have not been performed.

This review tries to establish first whether differences in outcome are observed between continuous and intermittent treatment modalities and second, whether an improvement in the outcome of patients with acute renal failure treated with continuous modalities of dialysis and ultrafiltration techniques occurred during the last 10 years. For that purpose all peer-reviewed publications of trials concerning the use of continuous forms of RRT with or without an intermittently treated control group were analysed. Studies available only as an abstract were not considered for the subsequent analysis.

\section{Studies comparing continuous with intermittent forms of renal replacement therapy}

Fifteen studies comparing intermittent ( 522 patients) with continuous (651 patients) forms of RRT have been published (Table 1). Whereas most studies reported observations from patient numbers between 
Table. 1. Studies comparing intermittent with continuous renal replacement therapies

\begin{tabular}{|c|c|c|c|c|c|c|c|c|c|}
\hline Author, year & $\begin{array}{l}\text { Number } \\
\text { of } \\
\text { patients }\end{array}$ & $\begin{array}{l}\text { Mean age } \\
\text { age } \\
\text { (years) }\end{array}$ & $\begin{array}{l}\text { MAP } \\
(\mathrm{mmHg})\end{array}$ & $\begin{array}{l}\text { APACHE } \\
\text { II }\end{array}$ & $\begin{array}{l}\text { Fluid } \\
\text { allowance } \\
\text { (1/day) }\end{array}$ & $\begin{array}{l}\text { Renal } \\
\text { recovery }\end{array}$ & Mortality & $\begin{array}{l}\text { Study } \\
\text { characteristics }\end{array}$ & Filter \\
\hline Mauritz, 1986 [8] & 58 & 50 & uk & uk & uk & 34 & 81 & re,nr & \\
\hline -HD & 22 & 52 & & & & 27 & 91 & & CDAK \\
\hline$-\mathrm{CAVH}$ & 9 & 51 & & & & 11 & 89 & & AMICON \\
\hline$-\mathrm{CVVH}$ & 27 & 47 & & & & 48 & 70 & & AMICON \\
\hline Bartlett, 1986 [16] & 56 & 57 & uk & 21 & uk & uk & 79 & re & \\
\hline$-\mathrm{HD}$ & 24 & 56 & & 21 & & & 88 & & C-Acetate \\
\hline$-\mathrm{CAVH}$ & 32 & 59 & & 21 & & & 72 & & AMICON \\
\hline Simpson, 1987 [7] & 32 & 50 & uk & 18 & uk & uk & 60 & re,nr & \\
\hline -cont UF/Dial. & 14 & 48 & & 17 & & & 50 & & $\mathrm{~F} 40 / \mathrm{F} 60$ \\
\hline$-\mathrm{HD}$ & 18 & 52 & & 18 & & & 67 & & Cuprophan \\
\hline Paganini, 1988 [3] & 142 & 62 & 75 & 31 & 3.2 & 17 & 79 & re,nr & \\
\hline -continuous & 27 & 65 & 65 & 36 & 3.8 & 19 & 81 & & uk \\
\hline -intermittent & 47 & 62 & 87 & 27 & 2.1 & 19 & 82 & & uk \\
\hline -combined & 68 & 60 & 71 & 31 & 3.8 & 15 & 76 & & uk \\
\hline Maher, 1989 [18] & 90 & 51 & uk & & uk & uk & 73 & re,nr & \\
\hline$-\mathrm{CAVH}(\mathrm{ev} .+\mathrm{IHD})$ & 65 & & & 26 & & & & & FH55 \\
\hline -CAVHD & 22 & & & 26 & & & & & AN69 \\
\hline$-\mathrm{HD}$ & 3 & & & 27 & & & & uk & \\
\hline Favre, 1989 [19] & 76 & uk & 88 & uk & uk & uk & uk & re,nr & uk \\
\hline$-\mathrm{CVVH}$ & 40 & & 79 & & & & & & \\
\hline$-\mathrm{HD}$ & 36 & & 98 & & & & & & \\
\hline Davenport, 1991 [15] & 22 & uk & uk & uk & uk & uk & uk & $\mathrm{p}, \mathrm{pr}$ & \\
\hline $\mathrm{HD}$ & & & & & & & & & FH77 \\
\hline CAVH/CAVHD & & & & & & & & & Hosp 2400 \\
\hline Bosworth, 1991 [13] & 320 & 60 & 79 & 26 & uk & uk & 68 & re,nr & Polyamid/ \\
\hline -continuous & 95 & & 70 & & & & 82 & & Polyacnitr \\
\hline$-\mathrm{HD}$ & 138 & & 85 & & & & 60 & & Cuprophan \\
\hline -combined & 87 & & 79 & & & & 76 & & as above \\
\hline Bastien, 1991 [12] & 66 & 57 & & 22 & uk & uk & 62 & p,nr & \\
\hline -HD & 32 & 54 & & 20 & & & 75 & & uk \\
\hline -CVVHD & 34 & 60 & 75 & 23 & & & 50 & & AN69 \\
\hline Kierdorf, 1991 [11] & 146 & uk & uk & uk & uk & uk & 86 & re & uk \\
\hline -CVVHF & 73 & & & & & & 78 & & \\
\hline$-H D$ & 73 & & & & & & 93 & & \\
\hline McDonald, 1991 [17] & 42 & 46 & uk & uk & uk & uk & 79 & re & \\
\hline -HD & 10 & 50 & & & & & 70 & & Cuprophane \\
\hline -CAVHD & 22 & 45 & & & & & 70 & & AN69S \\
\hline -HD/CAVHD & 10 & 44 & & & & & 80 & & as above \\
\hline Bellomo, 1993 [4] & 167 & 58 & uk & 27 & uk & uk & 65 & re,nr & \\
\hline$-\mathrm{CHDF}$ & 83 & 60 & & 28 & & & 59 & & AN69S \\
\hline$-\mathrm{CD}$ & 84 & 56 & & 26 & & & 70 & & Cuprophan \\
\hline Bellomo, 1993 [5] & 160 & 59 & uk & 27 & uk & uk & 65 & $\mathrm{re}+\mathrm{p}, \mathrm{nr}$ & \\
\hline$-\mathrm{CHDF}$ & 76 & 62 & & 29 & & & 59 & & AN69S \\
\hline$-\mathrm{CD}$ & 84 & 56 & & 26 & & & 71 & & Cuprophan \\
\hline Kruczynski 1993 [10] & 35 & 56 & uk & 27 & uk & uk & 55 & re,nr & \\
\hline -CAVH & 12 & 45 & & 26 & & & 25 & & Gambro \\
\hline$-\mathrm{HD}$ & 23 & 61 & & 28 & & & 82 & & F6/F60 \\
\hline Davenport 1993 [14] & 32 & 33 & 77 & 26 & uk & uk & uk & $\mathrm{p}, \mathrm{pr}$ & \\
\hline$-\mathrm{HF}$ & 12 & 33 & 82 & 22 & & & & & FH77 \\
\hline -CAVH/CAVHD & 20 & 33 & 74 & 28 & & & & & Hosp 2400 \\
\hline
\end{tabular}

HD, Intermittent haemodialysis, r, Randomization, CAVH, Continuous arteriovenous haemofiltration, pr, Partly randomized, CVVH, Continuous venovenous haemofiltration, $\mathrm{nr}$, No randomization, CHDF, Continuous haemodiafiltration, re, Retrospective, CD, Conventional dialysis (intermittent haemodialysis or acute peritoneal dialysis), p, Prospective, HF, Intermittent haemofiltration, uk, Unknown, CHF, Continuous haemofiltration, cont UF/Dial., Continuous haemodialysis with ultrafiltration, CAVHD, Continuous arteriovenous haemofiltration with dialysis, MAP, Mean arterial presure.

3 and 36 (intermittently treated groups) and 9-87 (continuously treated groups) respectively, there are some studies with more than a 100 patients $[3-5,11,13]$. Only four trials were carried out prospectively $[5,12,14,15]$ and there is no published prospective trial with complete randomization available.

The type of filter used was indicated in 12 investi- gations $[4,5,7,8,10,12-18]$. No study applied filters with the same material for the continuously and intermittently treated patients. Intermittent treatments were mainly carried out with cellulose-based filters $[4,5,7,8,13,16,17]$, whereas continuous forms of RRT were performed by polyacrylonitrile $[4,5,12-15,17,18]$, polysulphone $[7,18]$ or polyamide [13] filters. 
The mean age of the patients was indicated in all but three studies $[11,15,19]$ and ranged from 46 to 62 years. In only one study young patients (mean age 33 years) with a head injury were treated [14].

Results about mean arterial pressure were reported in only four of 15 publications $[3,13,14,19]$. These values were higher in all studies in the intermittent $(88 \pm 7 \mathrm{mmHg}$, mean $\pm \mathrm{SD})$ than in the continuous $(72 \pm 6 \mathrm{mmHg})$ groups $(P<0.05$; Wilcoxon signed rank test). This suggests that patients with low blood pressure and presumably haemodynamic instability were preferentially treated by a continuous dialysis modality.

APACHE II scores were reported in 10 studies $[3-5,7,10,12-14,16,18]$ and the mean values ranged from 18 to 31 . Two studies were excluded from further analysis $[13,18]$. One study reported only a mean APACHE II score for the whole study population [13] and the other study was incomplete with respect to the APACHE II scores [18].

Fluid allowance, often considered to be a criterion for choosing a continuous form of RRT was given in only one report [3]; it was higher in the continuously than in the intermittently treated group (3.8 vs 2.1 1/day).

Two therapeutic end-points were given, renal recovery $[3,8]$ and mortality $[3-5,7,8,10-13,16-18]$ (Table 1). Renal recovery was reported in two studies $[3,8]$. In none of them was a definition of renal recovery given. As a consequence of the paucity of results, no definite conclusion about the superiority of the method of RRT with respect to renal recovery can be made (Table 1). Mortality rate is known from 12 of 15 studies (Table 1). The values for mortality rate ranged between 55 and $86 \%$. In three investigations a statistically significantly lower mortality was found in continuously than in intermittently treated patients [10-12]. A similar difference was detected in a subgroup of patients from a further study [4].

Despite the non-randomized character of most studies and the many historical control groups (Table 1) for intermittent therapy all available studies [3-5,7,8,10-19] were pooled for further analysis. Weighted multivariate logistic regression analysis was used to examine the influence of APACHE II score, patient age and investigation year on patient mortality in the reviewed trials. Weighted least-squares minimization was done by weighting the loss function with $\mathrm{N}^{*} \mathrm{q}^{*}(1-\mathrm{q})[20]$, where $\mathrm{N}$ is the number of subjects in each pooled study and $\mathrm{q}$ is the reported gross mortality rate of the corresponding study. Dummy variables were introduced to test for possible differences between treatment modalities in the relationship of patient mortality and the above-mentioned independent variables [20].

Pooling all the patients from the published trials revealed a mean age of $58 \pm 7.1$ years in patients with ARF on intensive care units, a mean APACHE II score of $27 \pm 4.9$ and a mean mortality rate of $69 \%$. In Figure 1 the results are given separately for the years 1986, 1987, 1988, 1991 and 1993. For the other years no studies were available. The analysis of Figure 1
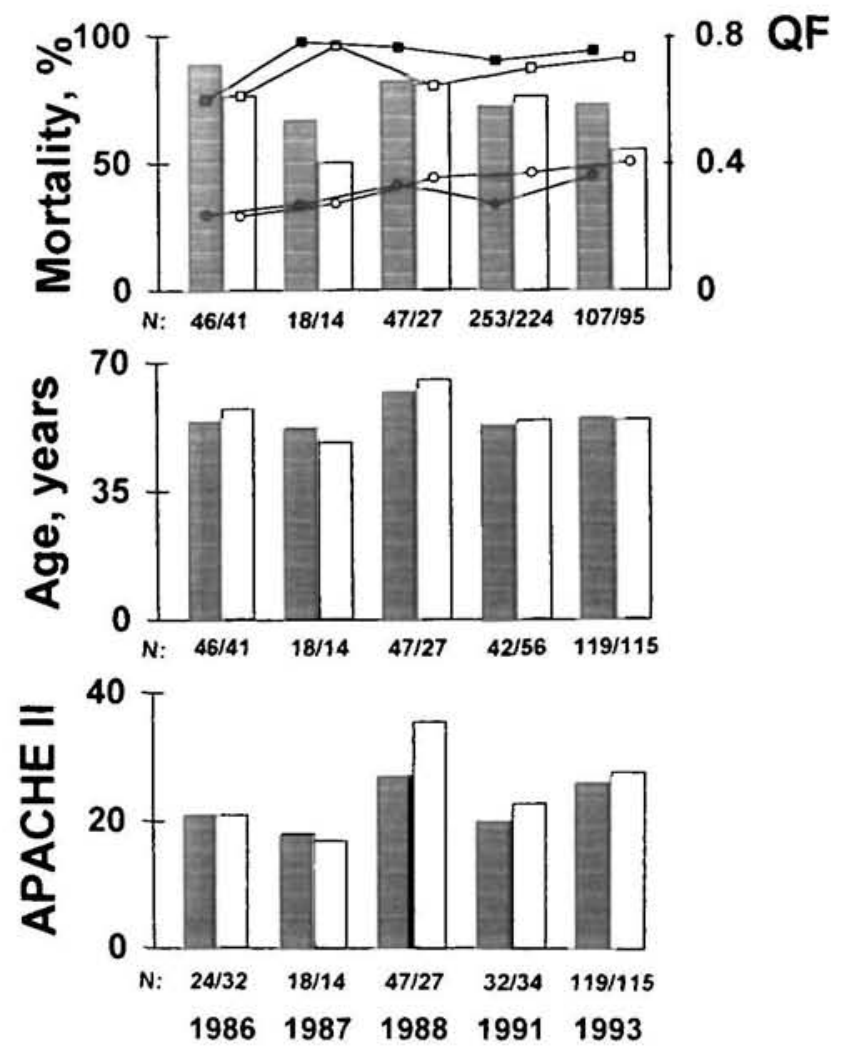

Fig. 1. Comparison of mortality rates, mean age and APACHE II scores between intermittently (hatched bars) and continuously (open bars) treated patients with ARF. The values were derived from studies published in $1986,1987,1988,1991$ or 1993. $\mathrm{N}$ indicates the number of patients analysed. In the upper part of the figure quality factors of treatment are shown. When age (- - intermittently treated patients; $-\square-$, continuously treated patients) or APACHE II (- - , intermittently treated patients; - $\mathrm{O}_{-}$, continuously treated patients) were considered for the calculation of the quality factors (QF) the values increased with time $(P<0.001)$.

shows a slightly decreasing mortality rate from $80 \%$ in 1986 to $64 \%$ in 1993 when intermittently and continuously treated patients were considered as a group. Logistic regression analysis, controlled for age, APACHE II score, observation year, and treatment modality, revealed a trend for a better outcome in recent years, independent of treatment modality $(P<0.07)$. However, no differences in mortality rates, APACHE II scores or mean age were detected between intermittent and continuous forms of RRT.

In order to establish whether the quality of treatment of patients with ARF increased in recent years one has to consider both, the severity of the underlying disease states and the mortality rates. The severity of the underlying disease, i.e. the likelihood of not surviving correlates with age and the APACHE II score [21]. Thus dividing age or APACHE II score by mortality rate provides a measure of quality of the treatment. In Figure 1 (upper part) we propose numerical values for such quality factors. For that purpose the weighted mean values of age and APACHE II score respectively, were divided by the corresponding weighted mean values of mortality. High values of those indices suggest 
good treatment quality whereas low values suggest the opposite. In Figure 1 the mean values from all studies from where such indices could be derived, are given (1986, 2 studies; 1987, 1 study; 1988, 2 studies; 1991, 5 studies; 1993, 4 studies). When analysed as a function of the year, treatment quality improved $(P<0.001$, weighted logistic regression analysis) as can be clearly shown by the steadily increasing quality factors (Figure 1).

\section{Studies reporting patients on a continuous form of renal replacement therapy without a control group}

An additional 52 studies describing only patients treated with continuous RRT without an intermittently treated control group were found in the literature $[2,6,9,22-70]$. The number of patients included in the reported studies ranged from five [23] to 255 [70] patients. The total number of patients reported in these 52 publications was 1860 .

Treatment modalities included continuous haemofiltration, either arteriovenous [23,26,28-32,37,45,$46,50-53,59]$, venovenous $[36,38,47,49,60,66]$ or both $[34,35,44,55]$, slow continuous ultrafiltration [6], continuous haemodialysis, either arteriovenous $[39,41,54,56,58,61,65,68]$, venovenous $[25,31]$ or both $[9,24,42,62,63]$, continuous haemodiafiltration $[40,48,67,69]$ as well as both continuous arteriovenous haemofiltration and haemodialysis $[43,57]$ respectively. In one study continuous RRT was combined with intermittent haemodialysis [29].

The types of filters used were mostly polyacrylonitrile $[9,24,25,28,31,33-35,37-42,48,53,58,61,65,66,68-70]$, but also polysulphone $[6,23,26,30,31,36,43,49-51,57]$ or polyamide $[32,44,46,47,51,55,56,58,70]$ filters have been used. In some studies the type of filter prescribed was not indicated.

Values for mean age are available from all but three trials $[37,45,63]$ and ranged between 38 years [62] and 73 years [41]. Mean APACHE II scores were available from 12 studies only $[9,24,25,33-35,39,58,59,61,64,66]$. The reported values were between $21[46,59]$ and 33 [39]. Mortality rates were given in all but six $[43,45,52,56,57,59]$ publications. These values ranged from $44 \%$ [31] to $100 \%$ [50].

Data from the 52 studies without a control group were pooled together with data from the continuous groups of the 15 studies with a control group discussed above (Table 1) in order to analyse the influence of patient age, APACHE II score and investigation year on patient mortality using the same logistic regression analysis as described above. When the mortality rate was analysed as a function of the year a trend to a steady decline was observed $(P<0.08)$ (Figure 2$)$. The APACHE II scores and the mean age of the patients did not change during the observation period. However the above defined quality factors of treatment increased as a function of time (Figure 2). For the calculation of these quality factors the following number of studies (year) could be considered: For the quality factor
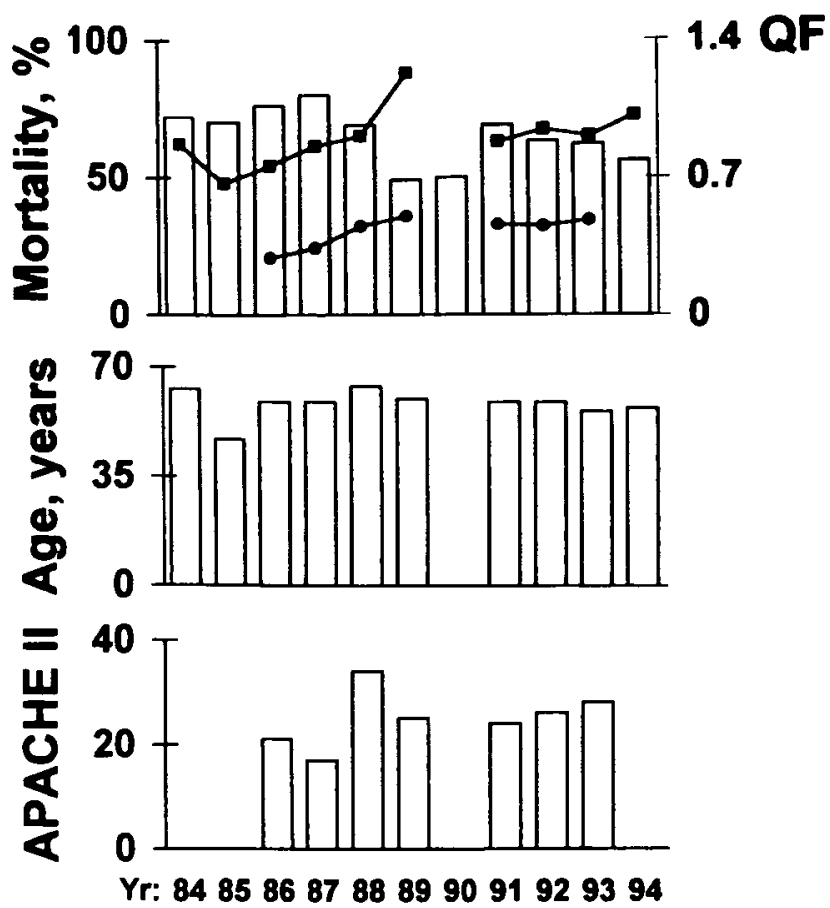

Fig. 2. Mortality rates, mean age and APACHE II scores from 1984 to 1994. Included are all published studies about treatment with a continuous modality of renal replacement therapy (number of patients: 2511). There is a trend to lower mortality rates in recent years, whereas mean age and APACHE II scores did not change. In the upper part of the figure the quality factors (QF) of treatment are shown. When considering age (- -) or APACHE II scores $(-)$ ) for the calculation of the quality factor a steady increase with time $(P<0.001)$ was observed for both parameters.

derived from mean age and mortality 16 (1991), 11 (1993), 8 (1988), 5 (1992), 4 (1989), 3 (1984, 1987), 2 (1986, 1994), 1 (1985), 0 (1990) and for the quality factor derived from mean APACHE II scores and mortality 7 (1993), 3 (1988, 1991, 1992), 2 (1989), 1 (1986, 1987), $0(1984,1985,1990,1994)$ respectively.

\section{Conclusions}

There is a steadily increasing pressure on the medical community in the western world to demonstrate improving quality of patient treatment. With respect to the treatment of ARF the difficulty to prove unequivocally a decreasing mortality rate over the last decade might be due to methodological problems, because the number of patients treated within a centre was relatively small, the case mix was heterogenous, and the treatment modality as well as the experience of the care providers changed as a function of time. As shown in the present review, a meta-analysis cannot be performed since not enough information about the various studies is available. In an attempt to get some qualitative information about the changes in the outcome all available studies using continuous forms of RRT have been pooled and the outcome analysed. This approach cannot exclude a publication bias and therefore the results have to be interpreted carefully. Within the 
limitations of this approach one can conclude that the quality of treatment improved as a function of time when the outcome determinants age and APACHE II score are used to correct for the changing patient population.

In a recent editorial about continuous and intermittent haemodialysis for acute renal failure on the intensive care unit Van Bommel [71] concluded that final proof for the superiority of continuous blood purification techniques to improve outcome in ARF has not been provided until now. That conclusion is supported by the detailed analysis of the literature presented in this paper. It is reassuring how many comparative trials have been performed in that field; however, it is surprising how incomplete these studies are when randomization, description of the patient population investigated, and assessement of therapeutic end-points are considered (Table 1). Furthermore, economic endpoints have virtually never been assessed in these studies. If in the future no advantage for the patients with respect to survival rate can be found when a continuous instead of an intermittent RRT is used, the sum of expenditures for material and labour might ultimately be pivotal for choosing the type of RRT. Thus, future studies designed to investigate the impact of the treatment modality on patient survival rate should comprise an economic assessement.

Acknowledgements. Grant support: Swiss National Foundation, $\mathrm{N}^{\circ} \cdot 32-36341.92$, D. E. Uehlinger.

\section{References}

1. Kramer P, Wigger W, Rieger J, Matthaei D, Scheler F. Arteriovenous hemofiltration: a new and simple method for treatment of over-hydrated patients resistant to diuretics. Klin Wochenschr 1977; 55: 1121-1122

2. Geronemus R, Schneider N. Continuous arteriovenous hemodialysis: a new modality for treatment of acute renal failure. Trans Am Soc Artif Intern Organs 1984; 30: 610-613

3. Paganini EP. Slow continuous hemofiltration and slow continuous ultrafiltration. Trans Am Soc Artif Intern Organs 1988; 34: $63-66$

4. Bellomo R, Mansfield D, Rumble S, Shapiro J, Parkin G, Boyce N. A comparison of conventional dialytic therapy and acute continuous hemodiafiltration in the management of acute renal failure in the critically ill. Ren Fail 1993; 15(5): 595-602

5. Bellomo R, Boyce N. Continuous venovenous hemodiafiltration compared with conventional dialysis in critically ill patients with acute renal failure. ASAIO J 1993; 794-797

6. Paganini EP, O'Hara P, Nakamoto S. Slow continuous ultrafiltration in hemodialysis resistant oliguric acute renal failure patients. Trans Am Soc Artif Intern Organs 1984; 30: 173-178

7. Simpson HKL, Allison MEM, Telfer ABM. Improving the prognosis in acute renal and respiratory failure. Ren Fail 1987; 10(1): $45-54$

8. Mauritz. W, Sporn P, Schindler I, Zadrobilek E, Roth E, Appel W. Akutes Nierenversagen bei abdomineller Sepsis. Vergleich von Hämodialyse und kontinuierlicher arteriovenöser Hämofiltration. Anästh Intensivther Notfallmed 1986; 21: 212-217

9. Bellomo R, Parkin G, Love J, Boyce N. Use of continuous hemodiafiltration: an approach to the management of acute renal failure in the critically ill. Am J Nephrol 1992; 12: 240-245

10. Kruczynski K, Irvine- Bird K, Toffelmire B, Morton AR. A comparison of continuous arteriovenous hemofiltration and intermittent hemodialysis in acute renal failure patients in the intensive care unit. $A S A I O J 1993 ; 778-781$
11. Kierdorf $\mathbf{H}$. Continuous versus intermittent treatment: Clinical results in acute renal failure. Contrib Nephrol 1991; 93: 1-12

12. Bastien O, Saroul C, Hercule C, George M, Estanove S. Continuous venovenous hemodialysis after cardiac surgery. Contrib Nephrol 1991; 93: 76-78

13. Bosworth C, Paganini EP, Cosentino F, Heyka RJ. Long-term experience with continuous renal replacement therapy in intensive-care unit acute renal failure. Contrib Nephrol 1991; 93: 13-16

14. Davenport A, Will EJ. Improved cardiovascular stability during continuous modes of renal replacement therapy in critically ill patients with acute hepatic and renal failure. Crit Care Med 1993; $21(3): 328-338$

15. Davenport A, Will EJ, Davison AM. Continuous vs intermittent forms of hemofiltration and/or dialysis in the management of acute renal failure in patients with defective cerebral autoregulation at risk of cerebral oedema. Contrib Nephrol 1991; 93: 225-233

16. Bartlett RH, Mault JR, Decker RE, Palmer J, Swartz RD, Port FK. Continuous arteriovenous hemofiltration: improved survival in surgical acute renal failure? Surgery 1986; 100: 400-408

17. Mc Donald BR, Mehta RL. Decreased mortality in patients with acute renal failure undergoing continuous arteriovenous hemodialysis. Contrib Nephrol 1991; 93: 51-56

18. Maher ER, Hart $L$ et al. Comparison of continuous arteriovenous hemofiltration and hemodialysis in acute renal failure. Lancet 1988; 2: 129

19. Favre H. Hemodialysis, peritoneal dialysis or continuous extracorporeal epuration in acute renal failure. Contrib Nephrol 1989; 71: $100-103$

20. Armitage P, Berry G. Statistical Methods in Medical Research Blackwell Scientific Publications, Oxford, 1987; 2nd edn

21. Knaus WA, Draper EA, Wagner DP, Zimmermann JE APACHE Il: a severity of disease classification system. Crit Care Med 1985; 13: 818-829

22. Sieberth $H G$, Kierdorf $H$. Is contınuous hemofiltration superior to intermittent dialysis and hemofiltration treatment. In: Hörl WH, Schollmeyer PJ, eds. New Perspectives in Hemodialysis, Peritoneal Dailysis, Arteriovenous Hemofiltration and Plasmapheresis. Plenum Press, New York, 1990; 181-192

23. Mault JR, Kresowik TF, Deckert RE, Amoldi DK, Swartz RD, Bartlett RH. Continuous arteriovenous hemofiltration: the answer to starvation in acute renal failure. Trans Am Soc Artif Intern Organs 1984; 30: 203-206

24. Bellomo R, Parkin G, Love J, Boyce N. A prospective comparative study of continuous arteriovenous hemodiafiltration and continuous venovenous hemodiafiltration in critically ill patients. Am J Kidney Dis 1993; 21 (4): 400-404

25. Bellomo R, Parkin G, Love J, Boyce N. Management of acute renal failure in the critically ill with continuous venovenous hemodiafiltration. Ren Fall 1992; 14(2): 183-186

26. Kaplan AA, Longnecker RE, Vaughn WF. Continuous ateriovenous hemofiltration-a report of six month's experience. Ann Intern Med 1984; 100: 358-367

27. Tam Py-W, Huraib S, Mahan B, LeBlanc D, Lunski CA: Holtzer C, Doyle CE, Vas SI, Uldall PR. Slow continuous hemodialysis for the management of complicated acute renal failure in an intensive care unit. Clin Nephrol 1988; 30: 79-85

28. Reynolds HN, Borg U, Belzberg H, Wiles CE III. Efficacy of continuous arteriovenous hemofiltration with dialysis in patients with renal failure. Crit Care Med 1991; 19(11): 1387-1394

29. Tominaga GT, Ingegno $M$, Ceraldi $C$, Waxman $K$. Vascular complications of continuous arteriovenous hemofiltration in trauma patients. J Trauma 1993; 35(2): 285-289

30. Alarabi AA, Brendolan A, Danielson BG, Raimondi F, Ronco C, Wikström B. Outcome of continuous arteriovenous hemofiltration in acute renal failure. Contrib Nephrol 1991; 93: 17-19

31. Alarabi AA, Danielson BG, Wikström B, Wahlberg J. Outcome of continuous ateriovenous hemofiltration (CAVH) in one centre. Ups J Med Sci 1989; 94: 299-303

32. Sluiter HE, Froberg L, van Dijl J, Go JG. Mortality in highrisk intensive-care patients with acute renal failure treated with continuous arteriovenous hemofiltration. Contrib Nephrol 1991; 93: $20-22$

33. Bellomo R, Parkin G, Boyce $N$. Acute renal failure in the 
critically ill: management by continuous veno-venous hemodiafiltration. J Crit Care 1993; 8(3): 140-144

34. Bellomo R, Boyce N. Acute continuous hemodiafiltration: a prospective study of 110 patients and a reviev of the literature. Am J Kidney Dis 1993; 21(5): 508-518

35. Bellomo R, Colman PG, Caudwell J, Boyce N. Acute continuous hemofiltration with dialysis: Effect on insulin concentrations and glycemic control in critically ill patients. Crit Care Med 1992; 20 (2): 1672-1676

36. Ponikvar R, Kandus A, Biturovic J, Kveder R. Use of prostacyclin as the only anticoagulant during continuous venovenous hemofiltration. Contrib Nephrol 1991; 93: 218-220

37. Chanard J, Milcent T, Toupance O, Melin J-P, Roujouleh $H$, - Lavaud S. Ultrafiltration-pump assisted continuous arteriovenous hemofiltration (CAVH). Kidney Int 1988; 33(24): $157-158$

38. Canaud B, Cristol JP, Berthelemy C, Klouche K, Beraud JJ, Mion C. Acute renal failure associated with multiple organ failure: Pump-assisted continuous venovenous hemofiltration, the ultimate treatment modality. Contrib Nephrol 1991; 93: 32-38

39. Stevens PE, Davies SP, Brown EA, Riley B, Gower PE, Kox W. Continuous arteriovenous hemodialysis in critically ill patients. Lancet 1988; 2:150-152

40. Keller E, Reetze-Bonorden P, Lückıng HP, Böhler J, Schollmeyer P. Continuous arteriovenous hemodialysis. Experience in twenty-six intensive care patients. Continuous hemofiltration. Contrib Nephrol 1991; 93: 47-50

41. Geronemus RP, Schneider NS, Epstein M. Survival in patients treated with continuous arteriovenous hemodialysis for acute renal failure and chronic renal failure. Continuous hemofiltration. Contrib Nephrol 1991; 93: 29-31

42. Schäfer GE, Döring C, Sodemann K, Russ A, Schröder HM Continuous arteriovenous and venovenous hemodialysis in critically ill patients. Contrib Nephrol 1991; 93: 23-28

43. Alarabi AA, Wikström B, Danielson BG. Continuous arteriovenous hemodialysis and hemofiltration in acute renal failure: comparison of uremic control. Contrib Nephrol 1991; 93: 61-64

44. Keusch G, Schreier P, Binswanger U. Outcome in critically il patients with acute renal failure treated by continuous hemofiltration. Contrib Nephrol 1991; 93: 57-60

45. Rau HC, Staubach KH, Hohlbach C, Klingler W. The continuous arterio-venous hemofiltration in shock. In: ed. Progress in Clinical and Biological Research. Vol. 236B. Alan R. Liss, New York 1987; 241-247

46. Bagshaw ONT, Anaes FRC, Hutchinson A. Continuous arteriovenous hemofiltration and respiratory function in multiple organ failure. Intensive Care Med 1992; 18: 334-338

47. Levy B, Clavey M, Burtin P, Dopff C, Hubert T, Villemot JP. Hémofiltration continue veinoveineuse après chirurgie cardiaque. Etude rétrospective chez seize patients en défaillance multiviscérale. Ann Fr Aneth Réanim 1992; 11:436-441

48. Freudiger $H$, Lévy $M$, suter $P$, Favre $H$. Hémodiafiltration continue veino-veineuse dans l'insuffisance rénale aiguë. Nephrologie 1990; 11: 129-133

49. Baudouin SV, Wiggins J, Keogh BF, Morgan CJ, Evans TW Continuous veno-venous hemofiltration following cardiopulmonary bypass. Indications and outcome in 35 patients. Intensive Care Med 1993; 19: 290-293

50. Chazot C, Gaussorgues P, Vedrnne C, Tigaud JM, Boyer F, Gerard M, Robert D. Quand débuter l'hémofiltration continue en réanimation? Presse Med 1987; 16(20): 1005-1006

51. Olbricht CJ, Haubitz M, Häbel U, Frei U, Koch K-M Continuous arteriovenous hemofiltration: In vivo functional characteristics and its dependence on vascular access and filter design. Nephron 1993; 55: 49-57

52. Chima CS, Meyer L, Hummell AC, Bosworth C, Heyka R,
Paganini EP, Werynski A. Protein catabolic rate in patients with acute renal failure on continuous arteriovenous hemofiltration and total parenteral nutrition. J Am Soc Nephrol 1993; 3 1516-1521

53. Ronco $\mathrm{C}$. Brendolan A, Bragantini L et al. Continuous arteriovenous hemofiltration with AN69S membrane; procedures and experience. Kidney Int 1988; 33 (24): 150-153

54. Schneider NS, Geronemus RP. Continuous arteriovenous hemodialysis. Kidney Int 1988; 33(24): 159-162

55. Storck M, Hart WH, Zimmerer E, Inthorn D. Comparison of pump-driven and spontaneous continuous hemofiltration in postoperative acute renal failure. Lancet 1991; 337: 452-455

56. Yohay DA, Butterly DW, Schwab SJ, Quarles LD. Continuous arteriovenous hemodialysis: effect of dialyzer geometry. Kidney Int 1992; 42: 448-451

57. Raja R, Kramer M, Goldstein S, Caruana R, Lerner AS Comparison of continuous arteriovenous hemofiltration and continuous arteriovenous dialysis in critically ill patients. Trans Am Soc Artif Intern Organs 1986; 32: 435-436

58. Gibney RTN, Stollery DE, Lefebvre RE, Sharun CJ, Chan P. Continuous arteriovenous hemodialysis: an alternative therapy for acute renal failure associated with critical illness. CMAJ 1988 ; 139: 861-866

59. Chima CS, Meyer L, Heyka $R$ et al. Nitrogen balance in postsurgical patients with acute renal failure on continuous arteriovenous hemofiltration and total parenteral nutrition. Contrib Nephrol 1991; 93: 39-41

60. Davenport A, Roberts NB. Amino acid losses during contınuous high-flux hemofiltration in the critically ill patient. Crit Care Med 1989; 17(10): 1010-1014

61. Davies SP, Reaveley DA, Brown EA, Kox WJ. Amino acid clearances and dally losses in patients with acute renal failure treated by continuous arteriovenous hemodialysis. Crit Care Med 1991; 19(12), 1510-1515

62. Frankenfield DC, Badellino MM, Reynolds HN, Wiles CE Siegel JH, Goodarzi S. Amino acid loss and plasma concentration during continuous hemodiafiltration. $J$ Parenter Enteral Nutr 1993; 17(6): 551-561

63. Sodemann K, Niedenthal A, Russ A, Weber C, Schäfer GE. Automated fluid balance in continuous hemodialysis with blood safety module BSM 22/VPM. Contrib Nephrol 1991; 93: 184-192

64. Maher ER, Robinson KN et al. Prognosis of critically ill patients with acute renal failure: Appache II score and other predictive factors. $Q J$ Med 1989; 269: 857-866

65. Ashton D, Mehta RL, Ward DM, McDonald BR, Aguilar MM. Recent advances in continuous renal replacement therapy: Citrate anticoagulated continuous arteriovenous hemodialysis. ANNA J 1991; 18(3): 263-267, 329

66. Wendon J, Smithies M, Sheppard M, Bullen K, Tinker J, Bihari $D$. Continuous high volume venous-venous haemofiltration in acute renal failure. Intensive Care Med 1989; 15: 358-363

67. Tominaga GT, Ingegno MD, Scanell G, V. Pahl M, Waxman K.. Continuous arteriovenous hemodiafiltration in postoperative and traumatic renal failure. Am J Surg 1993; 166; 612-616

68. Sigler MH, Brendan PT. Solute transport in continuous hemodialysis: A new treatment for acute renal failure. Kidney Int 1987; 32: $562-571$.

69. Frankenfield DC, Reynolds HN, Wiles CE III, Badellino MM, Siegel JH. Urea removal during continuous hemodiafiltration. Crit Care Med 1994; 22(3): 407-412

70. Martin PY, Chevrolet JC, Suter P, Favre H. Anticoagulation in patients treated by continuous venovenous hemofiltration: a retrospective study. Am J Kidney Dis 1994; 24(5): 806-812

71. Van Bommel EFH. Are continuous therapies superior to intermittent haemodialysis for acute renal failure on the intensive care unit? Nephrol Dial Transplant 1995; 10(3): 311-314 